\title{
Characterisation of Aluminium Matrix Syntactic Foams Under Static and Dynamic Loading
}

\author{
M. Altenaiji, G.K. Schleyer and Y.Y. Zhao \\ Additional information is available at the end of the chapter
}

http://dx.doi.org/10.5772/48560

\section{Introduction}

The resistance of engineering structures, subjected to blast and impact loads, is of great interest within the engineering community and government agencies. The interest and importance of such material stem from the need for providing protection against possible terrorist threats. Development of a light -weight, strong and ductile material capable of providing protection of vehicles and occupants against impact and blast, however, is a formidable challenge facing the materials community.

In a blast or an impact, a structure usually undergoes large plastic deformation or break. The important characteristics of structural response include: (i) mode of deformation and failure, (ii) impulse transfer, and (iii) energy absorption in plastic deformation (Hanssen et al., 2002). To characterize cellular materials, the characteristics of the base material of the foam, its relative density, type of its cells (open or closed) and the mean cell diameter, all of these must be known (Ashby et al, 1997). The characterization and testing of metallic foams require special precautions. A cellular material could be characterized by several parameters such as: the constituent raw materials, the mean cell diameter, relative density (porosity), and cell size and shape etc. The constituents can be analysed by using x-ray tomography, optical microscopy and scanning electron microscopy. The easiest way to measure porosity (relative density) is to weigh the sample of a known volume. Additionally, metal foam could be characterized by its cell topology (open cells, closed-cells). Characterizations of metal foam using optical microscopy can be carried out provide that the foam is fully impregnated with opaque epoxy resin before polishing. Scanning electron microscopy has been found to be most informative for open cells foams rather than for the closed-cell foams (Ashby et al., 2000). On the other hand, x-ray tomography technique is a good way to investigate the deformation modes of cellular solids. It depends on the low overall absorption of x-rays as such low absorption allows large specimens to be cut into small pieces. The second 
advantage of this technique is the fact that the deformation could be monitored nondestructively (Fazekas et. al, 2003).

The mechanical properties of cellular materials can be characterized by the compression test. The behaviour of the cellular material under static- compression is known to be completely different from that of the solid material without any compression. This test is also used for the study of the behaviour of material under crushing load. The compression test is useful for measuring plastic flow, ductile fracture limit and compressive fracture properties of brittle materials. In a compression, several modes of deformation can may occur as illustrated in Figure.1. These are as follows: a) buckling mode when the ratio of the sample height $(\mathrm{h})$ to its width $(\mathrm{w})$; i.e. $(\mathrm{h} / \mathrm{w})>5 ; \mathrm{b})$ shearing mode may appear when $(\mathrm{h} / \mathrm{w}) \sim 2.5$; and, c) double barrelling when ratio of length (L) and diameter (D) i.e. (L/D) $>2$ and friction is presented at contact surfaces, d) barrelling mode when $(\mathrm{h} / \mathrm{w})<2$; e) a homogenous compression mode when the ratio $(\mathrm{h} / \mathrm{w})$ lies between 2.0 and 1.5 and finally; $\mathrm{f}$ ) the possibility of compressive instability (Medlin \& Kuhn, 2000).

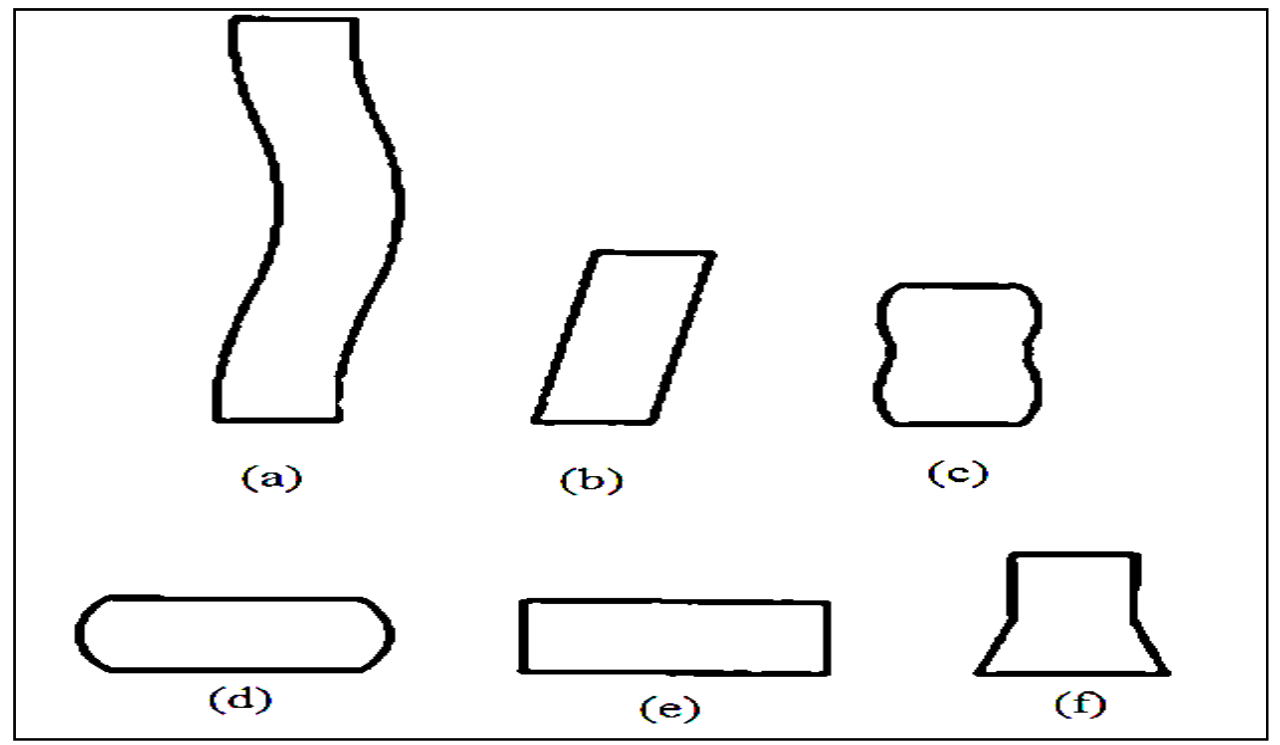

Figure 1. Modes of deformation in a compression test (Medlin \& Kuhn, 2000).

The study of the compressive behaviour of cellular materials offers the benefit of knowledge on most of the mechanical properties of the material. The mechanical properties of cellular materials are different to its base material due to the difference in structures. The following section explains the compressive properties of cellular materials and its relevance to their myriad applications.

Stress-strain curve is used to determine Young's modulus which, in turn, yields values of strength and strain densification. An example of a typical stress-strain curve (Gibson, 2000) of cellular material under uni-axial compression test condition is shown in Figure.2. Stress- 
strain curve of metallic foam shows three regimes of material behaviour. As can be seen in the graph, initially it is a linear dependence of elasticity (strain) with stress. Such dependency is governed by the strength of cell walls of the base material. As is expected, the stiffness of the metallic foam will be higher with the increase of strength of the cell wall. It has been observed that the type and grade of metallic alloy as the base material dictate the stiffness of the foam structure. It has been found that the metallic alloy which has higher yield strength, gives higher stiffness than other alloys. At this stage, the material undergoes a non-permanent deformation. Usually, the deformation is in the form of cell face stretching and consequently extending and stretching the cell edges. This, in turn, increases the stiffness which was driven by the cells edges in closed-cell foam configuration while extending and bending deformation mode in open cell foam configuration.

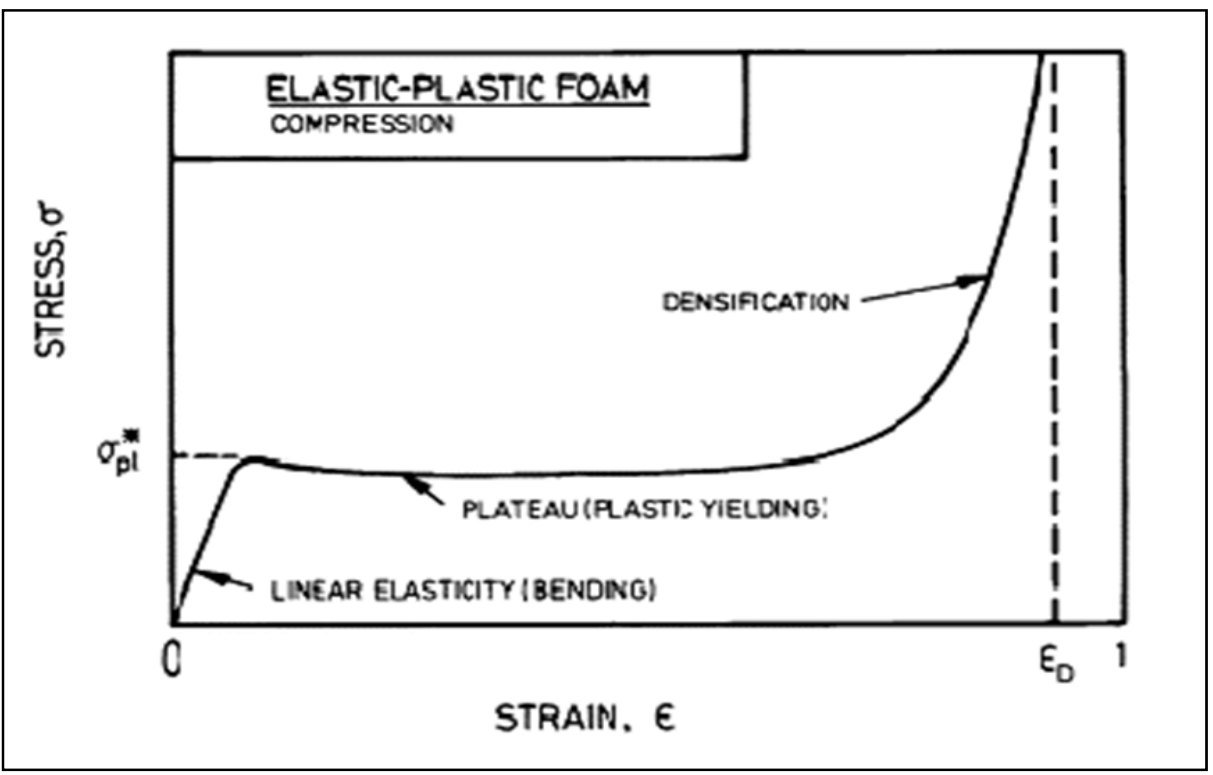

Figure 2. A typical stress-strain curve for foam showing linear elastic, stress plateau and densification regimes (Gibson, 2000).

Energy absorption is the ability of the material to convert the kinetic energy into energy of some other form such as, heat, viscosity, visco-elasticity, friction etc. The kinetic energy must be less than the maximum limit of energy absorption of the material to keep the object safe. Also, the energy absorption property must be multi-directional, i.e. allowing absorption of the impact from any direction. Cellular materials have better capacity of energy absorption than its base materials. Foams have a capability to absorb the kinetic energy by bending, buckling or fracture (plastically) of the cell walls depending on the characteristics of the base material of the foam (Ashby, 1997).

Energy absorption capability of foams depends on the stress and strain of the plateau in stress-strain curve. Foams have long, flat stress-strain curve where the cell walls collapses 
plastically to nominal strain $\varepsilon \mathrm{D}$ at a constant stress and the phenomenon is called, 'the plateau stress up'. The plateau stress must be below the value that causes damage to the object. The best energy absorbing material is that which has the longest plateau and absorbs the most energy before reaching the densification strain. The material that has a long and flat stress-strain curve is considered to be an ideal energy absorber. The energy absorber capability of the material is measured by the length and height of the flat stress-strain curve. The area under the plateau of the stress-strain curve represents energy per unit volume which can be absorbed as illustrated in Figure 3. The area under the flat part of the curves is the useful energy per unit volume, $\mathrm{W}_{\mathrm{v}}$ that can be absorbed.

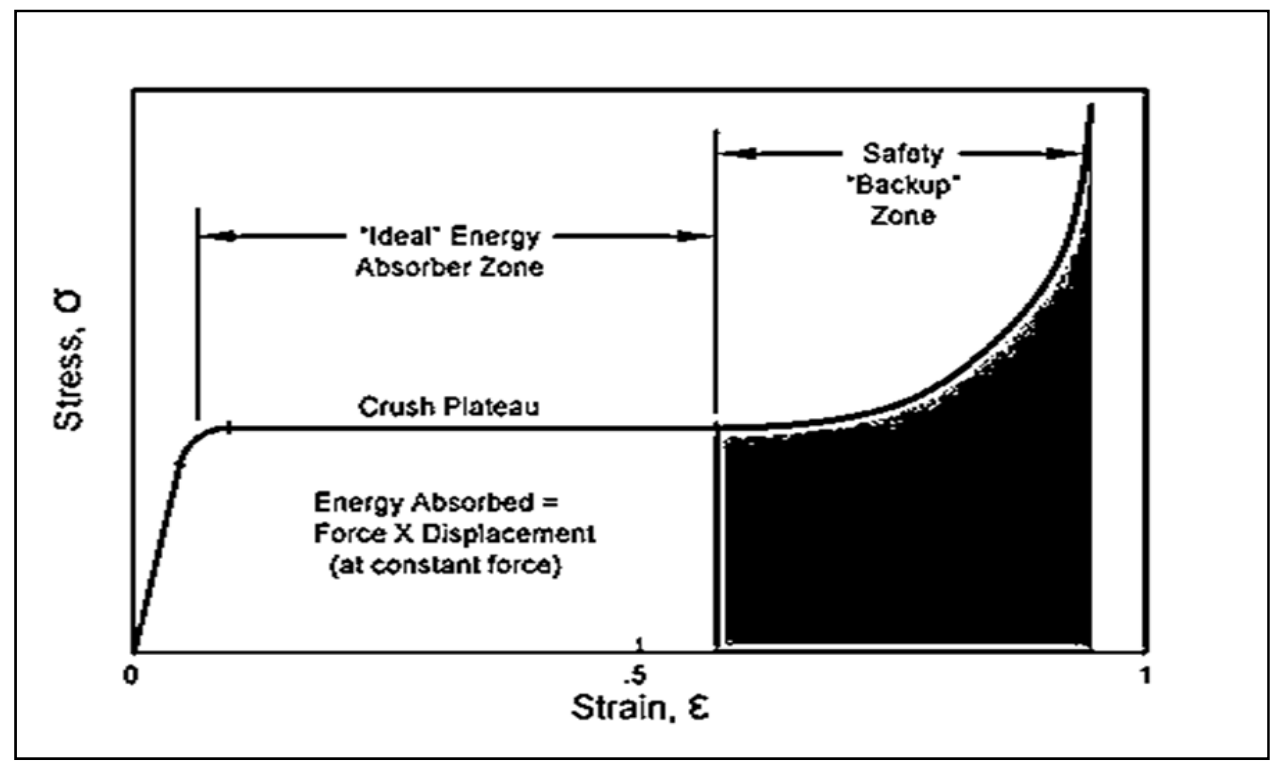

Figure 3. A typical stress-strain curve for an energy absorber.

\section{Metal matrix syntactic foam}

Matrix syntactic foams are composite materials consisting of a matrix implanted with hollow or porous ceramic particles. These foams are a new class of materials which are manufactured by a variety of metal or polymer matrices and micro-spheres ceramics. It consists of a metal matrix and micro-spheres ceramics, embedded in the matrix. A metal matrix could be of aluminium, steel, titanium or magnesium. Ceramic micro-sphere could be a porous or hollow structure, but hollow metal spheres are rarely used.

The size of the hollow ceramics micro-sphere determines the porosity of the matrix syntactic foam. In addition, it has an effect on the strength of the syntactic foam. Therefore, the matrix syntactic foam has different physical and mechanical properties than other cellular materials. Matrix syntactic foam is considered as a light material having high energy absorption capacity. It has been used in automotive, naval, aerospace and other industries 
where 'light-weight' property is an essential requirement. In addition to that it could be used for reducing shock loadings associated with mine blast on military vehicles where the high energy absorption capability and light weight property are needed.

\subsection{Fabrication process}

Metal matrix syntactic foams consist of a combination of ceramic micro-sphere and metal matrix. Most metal matrices should be light metals like aluminium, magnesium, titanium etc. Two types of micro-sphere in common use have either porous or hollow structures. Four types of cellular spheres have so far been used to fabricate metal matrix syntactic foam as follows: (i). amorphous silica, (ii). $\mathrm{Al} 2 \mathrm{O} 3$ spheres, (iii). CMs of crystalline mullite and (vi). steel spheres (Tao, 2010).

There are two main ways to fabricate metal matrix syntactic foams as follows: i) stir casting with spray processes, and ii) infiltration casting using liquid state. In stir casting, metal matrix syntactic foams are fabricated by mixing a liquid of metal matrix with the ceramic particles followed by casting. This method is very simple and cheap, but inhomogeneous structure of syntactic foam has been found to appear due to float of ceramic spheres to the top of the melt. In infiltration casting, the metal matrix is placed above the ceramic spheres and is pressed to infiltrate into the ceramic sphere where it is solidified to produce metal matrix syntactic foam. The infiltration casting can be conducted by gas pressure or die casting. This method has the advantage that the matrix and ceramic spheres are well bonded and the micro-spheres are usually uniformly distributed.

\subsection{Porosity}

There are two classifications for porosity: open or closed types. The open porosity is defined by the ratio of the volume of void space that is accessible from exterior to bulk volume. Meanwhile, the closed porosity is defined by the ratio of the volume of void space that is not accessible from exterior to bulk volume. The porosity of foams depends on the shape and size of the pores. The porosity of metallic syntactic foams, however, is determined by the porosity of the cellular spheres. The strength of the micro-sphere of syntactic foam could be tailored through the appropriate selection of the wall thickness and the radius of microspheres (Kiser, 1999). The porosity of cellular materials controls the plateau strength and energy absorption capacity of the foams. In general, the strength of porous materials increases with the reduction of porosity.

The main parameter that has the most significant effect on the porosity of the metal matrix syntactic foam is the porosity of the ceramics micro-spheres. The radius, shell thickness and the volume fraction of the hollow spheres are the parameters that control the porosity of hollow spheres. The porosity of a ceramic sphere could be estimated by the following equation (Kiser et. al, 1999):

$$
\theta_{\mathrm{s}}=\left(1-\frac{\rho_{\mathrm{s}}}{\rho_{\mathrm{o}}}\right)
$$


Where, $\theta \mathrm{s}$ is the porosity of ceramic material, $\mathrm{Q}_{\mathrm{s}}$ is its effective density and $\mathrm{Q}_{0}$ is the density of the solid part of the spheres. In principle the porosity of metal matrix syntactic foam may be calculated using the formula below (Zhang\& Zhao, 2007):

$$
\theta_{\mathrm{f}}=\left(1-\mathrm{f}_{\mathrm{al}}\right) \theta_{\mathrm{s}}
$$

Where, $\theta_{\mathrm{f}}$ is the porosity of syntactic foam and $f_{\text {al }}$ is the volume fraction of metal matrix. The authors have developed a general formula that has been widely used to calculate the porosity of metallic syntactic foam for all types of spheres and is given below:

$$
\theta_{\mathrm{s}}=\frac{\rho_{\mathrm{m}}-\rho_{\mathrm{f}}}{\rho_{\mathrm{m}} \rho_{\mathrm{s}}}\left(1-\frac{\rho_{\mathrm{s}}}{\rho_{\mathrm{o}}}\right)
$$

Where, Qm, Qf are Qo are the density of metal matrix, syntactic foam and solid part of cellular spheres respectively, and os is the effective density of the cellular spheres (Tao, 2010). It was reported earlier (Kiser et. al, 1999) that the thickness and the radius of the shell of the hollow sphere and the micro-balloon do control the composite porosity @o and developed a formula to calculate the porosity of syntactic foams with hollow spheres as follows:

$$
\rho_{\mathrm{o}}=\mathrm{f}\left(1-\frac{\mathrm{t}}{\mathrm{R}}\right)^{3}
$$

Where, $\mathrm{Q}_{0}$ is the porosity, $f$ is the volume percentage of the hollow spheres, and $t$ is the shell thickness and, $\mathrm{R}$ is the radius of the hollow spheres. It was also reported [Kiser et.al, 1999] that the strength of the micro-balloon could be tailored through appropriate selection of the parameter, $[t / R]$, having the strength increasing with increasing factor, $[t / R]$.

\subsection{Compressive strength of metallic matrix syntactic foam}

The compressive strength of metallic matrix syntactic foam is controlled by the strength of metal matrix and the ceramic particles. The parameters such as: volume fraction, structure and distribution of the ceramics particles have considerable effect on the properties of syntactic foams (Zhao\& Tao, 2009). It has been reported (Rohatgi et. al, 2006) that the compressive strength of the metallic syntactic foams decreases with the increase in volume fraction of the micro-spheres ceramics. In fact, the compressive strength of metal matrix has been found to be higher than that of the micro-spheres ceramics. Consequently the strength of the metallic matrix syntactic foam decreases with the increase in the volume fraction of ceramics particles.

It has been reported that the yield strength of metallic foam decreases with the decrease of the size of micro-spheres ceramic (Rohatgi et. al, 2006). Moreover, it has been noted (Altenaiji et.al, 2011) that the smaller the size of the micro-sphere ceramic, the weaker is the strength of metal matrix syntactic foam. There are also other parameters, such as the strength of the metal matrix, which effect the strength of metal matrix syntactic foam as illustrated in Figure 4 and Figure 5.

In contrast, Palmer reported (Palmer et. al, 2007) that, the lower compressive strength of metallic syntactic foams is associated with larger micro-spheres. It was however predicted 
(Zhao\& Tao, 2009) that there should be a difference in the compressive strength of different void contents in different sized ceramic spheres. It was also predicted (Sun et.al, 2007) that the thickness and the radius of micro-spheres ceramics have an effect on the compressive strength of metallic syntactic foams. The micro-sphere ceramics which have higher wall thickness to radius ratios $(t / r)$ were found to have higher compressive strength of the resultant. Earlier reports (Kiser et. al, 1999) indicated that the compressive strength of metal matrix syntactic foam increased from 70 to $230 \mathrm{MPa}$ with the increase of the factor, $(\mathrm{t} / \mathrm{r})$ from 0.12 to 0.48 , i.e. an increase by a factor of 3 for a similar factor of increase in the pressure.

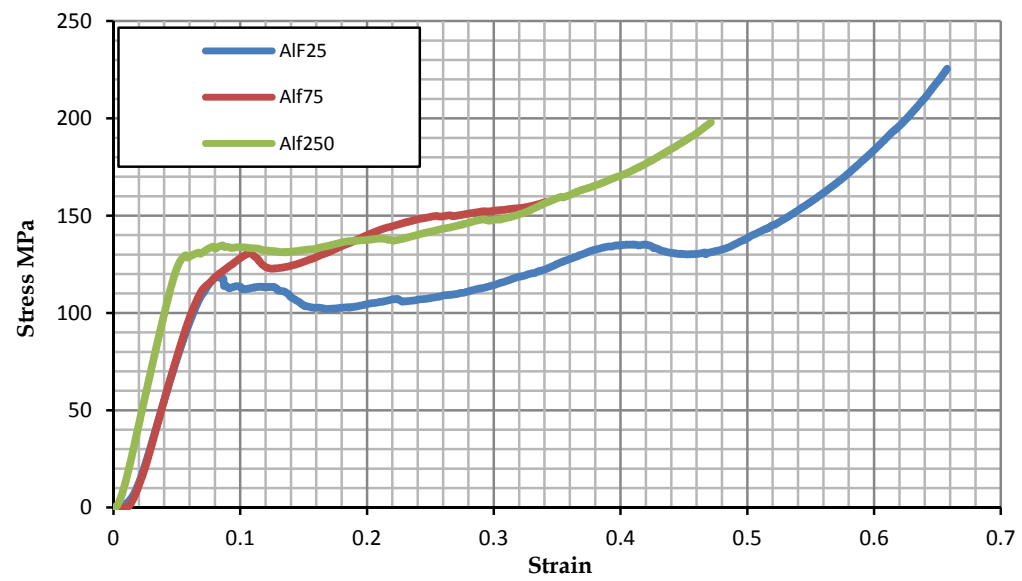

Figure 4. Comparison of stress-strain curve of aluminium syntactic foam with different ceramic microsphere size.

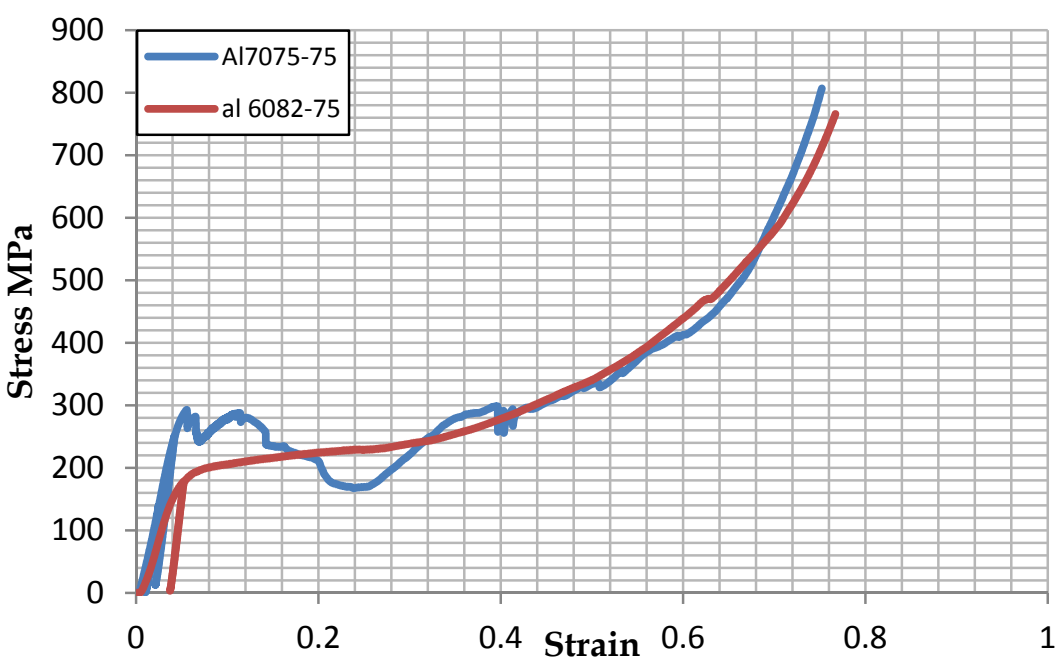

Figure 5. Comparison of stress-strain curve of aluminium syntactic foam with different aluminium matrix. 
The compressive strength of metallic matrix foams is also affected by the types of microspheres ceramics. It has been found that metallic matrix foam containing hollow ceramics spheres have much higher compressive strength than those containing porous ceramics spheres (Tao et.al, 2009). The compressive behaviour of metal matrix syntactic foams with hollow steel spheres of same thickness but different composition was studied (Vendra \& Rabiei, 2007). It was observed that the metal matrix, containing low carbon steel spheres had much lower compressive strength than the ones which had stainless steel spheres.

It has been reported that the compressive strength of the metal matrix syntactic foams is also affected by the type of metal matrix. Studies on the compressive behaviour of syntactic foams with same ceramics micro-sphere but different aluminium matrix had been conducted. It was found that the compressive strength of al7075-t is double that of al 6082-T with same method of processing. It was also indicated that when the aluminium matrix was replaced by another metal matrix the compressive strength of metallic matrix syntactic foams changed. When the al 7075 was used the compressive strength of metallic matrix syntactic foams had increased to approximately double than that containing pure aluminium (Balch\& Dunand, 2006).

\subsection{Failure of metallic matrix syntactic foam under compressive loading}

As is illustrated in Figure.2, metallic matrix syntactic foam behaved like any foam under compression loading. It has three regimes of behaviour under compression loading. Initially it starts with a linear elasticity and then follows by plateau strength and finally, ends by the densification strain. But, the failure behaviour of metal matrix syntactic foams is different due to it compositions. Its failure is controlled by different plastic characteristics. It can be either ductile, susceptible to collapse under crushing of micro-spheres ceramics or brittle, susceptible to shear failure (Balch et.al, 2005).

It was reported (Zhao\& Tao, 2009) that the three factors that affect the failure behaviour of metal matrix foam are: i) ductility of metal matrix, ii) structure of micro-spheres ceramic and, iii) volume fraction of micro-spheres ceramic and metal matrix. It is also reported that the behaviour of 'metal matrix syntactic' foams' performance failure depends on the type of the metal matrix. It was found that the aluminium alloy-T6 had two localized deformation bands of crushed materials while, the CP-Al (commercial purity aluminium) exhibited transition into densification plateau, showing extensive barrelling and pore deformation over a large volume of the material. Additionally, the damages of these two foams were reported to be different. In the alloy-T6, damage was concentrated in two much thicker crush band where the strain was very high. In contrast, in the CP-Al foams' damage was spread over a big volume of the material, resulting in plastic deformation of the matrix along with sphere fracture (Balch et.al, 2005).

It has been reported (Tao \& Zhao, 2009) that the compressive failure of metallic matrix syntactic foam is affected by the volume fraction of metal matrix micro-spheres ceramic. High volume of metal matrix causes ductile failure in the form of collapse of the material. In contrast, low volume of the metal matrix tends to cause brittle failure in the form of shear. 
As mentioned previously, the thickness and the radius of micro-spheres ceramics have an effect on the compressive strength of metallic syntactic foams. The micro-sphere ceramics with higher wall thickness-to-radius ratios, $(t / r)$ were found to have higher compressive strength for the resultant (Sun et.al, 2007). The syntactic foam metal matrix with low values of the ratio, $(t / r)$ failed as brittle failure form while those with higher values failed as ductile failure form also known as crushing or collapse failure form (Kiser et.al,1999) . In contrast, another report (Sun et.al, 2007) stipulated that the metal matrix syntactic foam with low values of the ratio, $(\mathrm{t} / \mathrm{r})$, failed as ductile in the form of crushing or collapse failure while that had higher values failed as brittle in the form of shear failure. It was, however, reported earlier (Gupta et.al, 2004) that different types of syntactic foams in which the matrix materials and the radius of micro-spheres were fixed while the wall thickness of the micro-spheres was varied. It had been found that failure type of different matrix syntactic foams was similar. In general, therefore, it may be concluded from the present up-to-date literature review that the value of the wall thickness to radius ratio $(t / r)$ dictates the form of the compressive failure of metal matrix syntactic foams while the value of the ratio is dependent upon the factor that affect the compressive failure. Furthermore, the strength of the micro-spheres ceramic has an effect on the strength of metal matrix syntactic foams.

\section{Dynamic compressive testing of matrix syntactic foam}

Metal matrix syntactic foams have been compressive tested under dynamic loading. Such loadings can be carried out through, either low or high speed impact. It has been studied under drop weight and split pressure Hopkinson bar test methods. It has been observed (Dou et.al, 2007) that the dynamic stress-strain curve has three regimes as the quasi-static stress strain curve. Meanwhile, the yield strength of metal matrix syntactic foams under dynamic loading is $\sim 45-60 \%$ higher than that of quasi static compression. Moreover, Zhang investigated (Zhang\& Zhao,2007) four samples of aluminium matrix syntactic foams under impact and reported that many oscillations appeared at the beginning of stress strain curve where the strain is low due to the high vertical vibration of the drop hammer. In addition, it was found that, out of four samples tested two had 10\%-30\% higher plateau stress than that of a quasi-static compression but the other two had lower plateau stress than that of the quasi-static compression. Therefore, the plateau strength is mostly determined by the volume fraction of metal matrix in the metallic syntactic foam. It was evaluated from the behaviour of aluminium matrix syntactic foams under high impact loading (Balch et al., 2005). Split pressure Hopkinson bar technique was used to characterize the material under dynamic loading. It was concluded that, the behaviour of aluminium matrix syntactic foams at high strain had higher peak strength and plateau stress than those measured during quasi-static testing. In addition, the peak strength of the stress strain curve has been found to have shifted slightly at higher strain value.

\subsection{Low velocity dynamic loading}

Low velocity dynamic loading has been conducted by using many facilities that include the Charpy and Izod pendulums, the drop weight fixture such as the Gardner as well as 
hydraulic machines, designed to conduct both in plane and out of plane testing at velocities up to $10 \mathrm{~m} \mathrm{~s}^{-1}$ (Cantwell\& Morton, 1991) The Charpy pendulum is simple to use and its design scheme is presented in Figure. 6. Usually, thick beam specimen is used which has a notch in the middle. The notch must be fixed opposite to the impact of the swing pendulum. The energy dissipated during impact is calculated by multiplication of the weight of the pendulum and the difference of the pendulum height in each side. The disadvantage of this test is that the high frequency oscillation on 'load versus time' curves due to natural frequency of the hammer does introduce error.

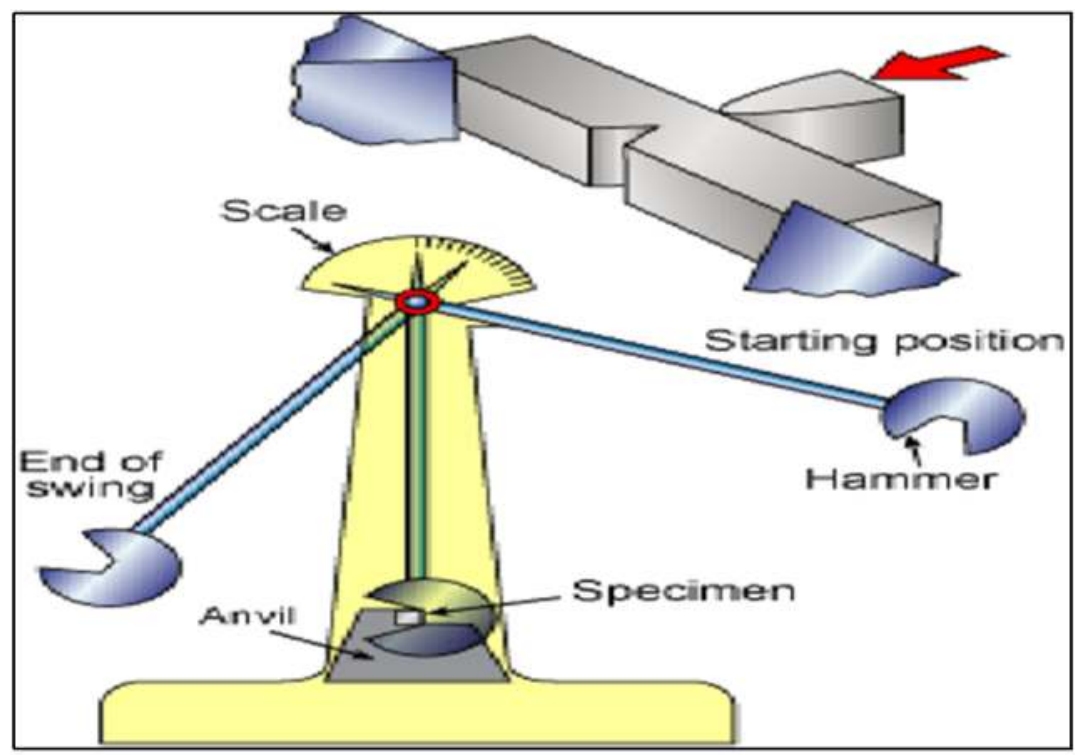

Figure 6. Schematic of the Charpy pendulum-type tester.

Comparatively, the Izod test is similar to the Charpy pendulum test except that the notch is located at the end of the specimen and the hammer impacts at the free end (Ellis, 1996). Cantwell and Morton suggested that Chapy and Izod tests both are suitable for evaluating the impact performance of the materials and a step in determining the dynamic toughness of the materials. In addition, drop-weight impact test have been used to conduct low velocity dynamics compressive testing of composites at strain rates ranging from 10 to several hundred per seconds (Hsiao et.al, 1998a, 1998b).

The heavy weight is guided by two smooth steel rails and fall from a height to strike the specimen (Fanjing, 2010). The impact of falling weight does not cause destruction of the test specimen but rebounds where the residual energy could be determined (Cantwell\& Morton, 1991) as shown in Figure.7.

A piezoelectric load cell is used to measure the variation of load with time during impact. It is located underneath the base on the test rig (Yiou, 2009). While, the incident velocity of the impactor can be determined from the equation of motion as follows: 


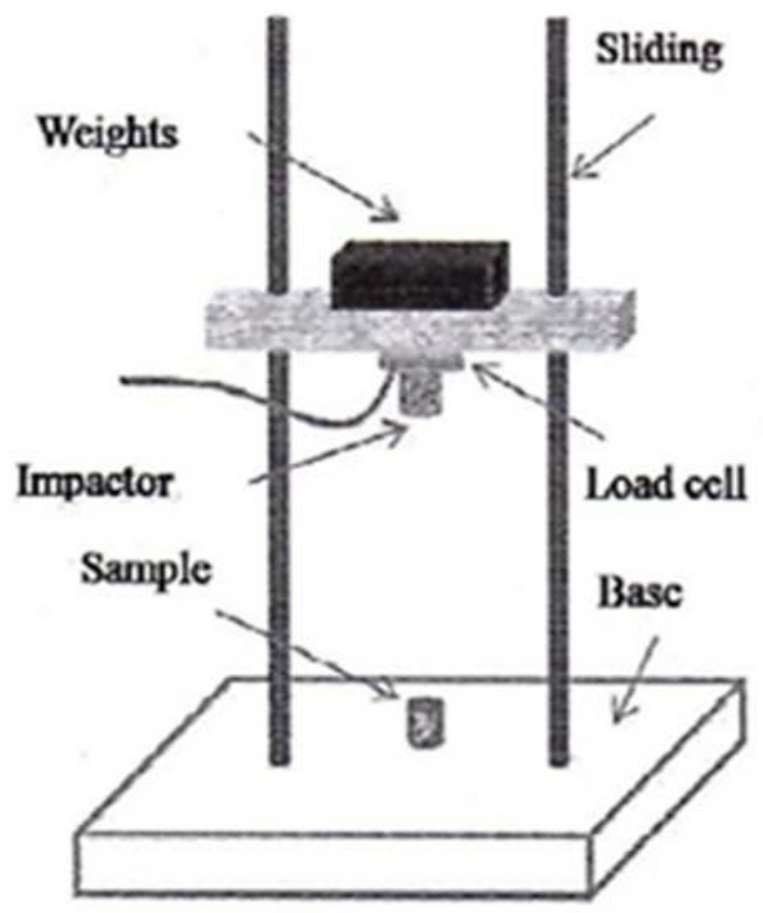

Figure 7. Schematic of the drop- hammer weight rig.

$$
\begin{gathered}
\mathrm{v}=\sqrt{ }(2 \mathrm{gh}) \\
\frac{\mathrm{a}}{\mathrm{g}}=\frac{v \omega}{\mathrm{gD}}
\end{gathered}
$$

where $\mathrm{V}, \mathrm{w}$ and $\mathrm{D}$ are the weight velocity, natural frequency and dynamic load factor (usually equal to 1.77) respectively (Rajendran et.al, 2008).

And predicted deflection is given as:

$$
\delta=\frac{\mathrm{mgh}}{\sigma_{\rho 1} \mathrm{~A}}
$$

where, $\mathrm{m}, \mathrm{h}, \mathrm{g}, \sigma_{\mathrm{ol}}$ and $\mathrm{A}$ are the weight mass, height of drop weight, gravitational force ,plateau stress and cross section area of sample respectively. The advantage of the dropweight impact test with respect to Chapy and Izod test is that a wider range of sample geometries can be tested by changing the support size and shape. However, the stress wave reflection effect on the stress-time response of the specimen is observed in this method. Also, the limitation of strain rate which depends on the speed of falling weight was found to be directly linked to the drop height (Barre et.al, 1996). Furthermore, hydraulic test machines have been used to characterise the deformation and failure of the materials at high strain rate (Beguefin \& Barbezat, 1989). One advantage of this type of testing machine is that it practically removes the problem of vibration noise that appears when using the drop 
weight test. Additionally, the limitation of the strain rate is extended up to a value of $50 \mathrm{~s}^{-1}$ from the static strain rate value. However, caution should be exercised to ensure that mass of the load cell is as low as possible to avoid the concealment of the true material response (Beguefin \& Barbezat, 1989).

\subsection{Medium and high velocity dynamics loading}

Medium and high velocity dynamics loading has been conducted by using many facilities that include Hopkinson bar and Gas gun. In the Hopkinson bar technique, the induced wave propagation in a long elastic metallic bar has been used to measure the pressure produced during dynamic events (Kolsky, 1949). The Hopkinson bar test was used to measure the dynamic stress-strain response of materials. A high precision strain gages, signal conditioners, and high speed digital oscilloscopes are used in Hopkinson bar with high sensitivity and accuracy. The sensitivity of the pressure bar is determined by the properties of the material of the bar such as the density and the elastic wave impedance (Ramesh, 2008). In addition, the type of stain gages and the characteristics of the associated instrumentations have an effect on the sensitivity.

To determine the properties of the material under dynamics loading the procedures for the Hopkinson bar technique is similar to that of the dynamic technique mentioned earlier. These are used to provide complete stress strain data as a function of strain rate. This technique has been used to determine the dynamic properties of numerous engineering materials like ferrous and non-ferrous alloys, polymers, ceramics, and concrete (Tan et.al, 2005). Additionally, it has been used to characterise soft materials and metal foams that have low mechanical impedance, required for increasing the sensitivity of testing device (Dung et.al, 2011; Gay III et.al, 2000; Chen et.al, 1997). Split Hopkinson pressure bar has been used to measure the compressive mechanical behaviour of materials, to load samples with uniaxial tension (Klepaczco et.al, 1997) and to measure compression torsion (Gilchrist, 2009). Also, it has been designed to measure the fracture toughness of an impact loaded material (Krauthauser, 2003).

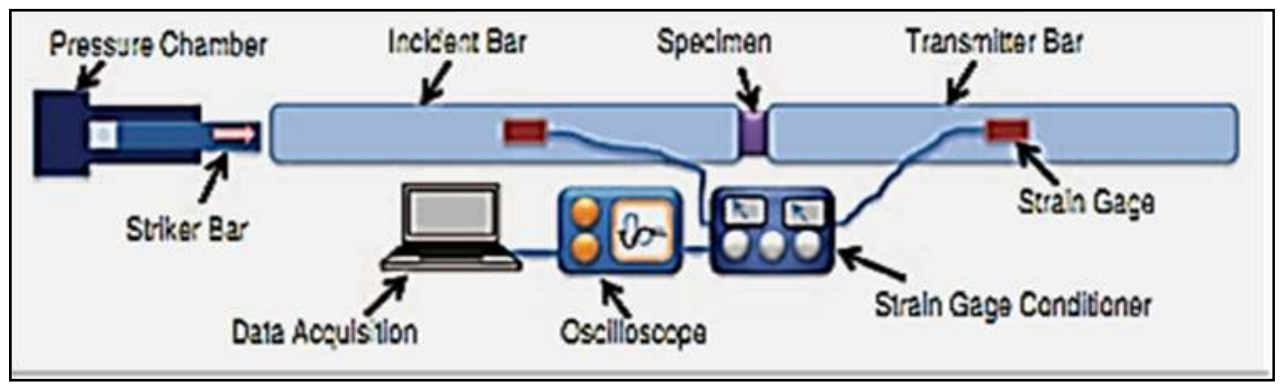

Figure 8. Schematic SHPB (Split Hopkinson pressure bar) setup for high strain rate compression testing

Before providing impact in an SHPB device the velocity of the striker was measured using an electronic velocity measurement unit. The gas gun pressure was varying that cause the 
variant impact velocities. The incident and transmitter bars in the device are made of steel having a length of $1000 \mathrm{~mm}$ and a diameter of $20 \mathrm{~mm}$. The bar's mechanical properties are: Young's modulus, $207 \mathrm{GPa}$, elastic wave speed, $5890 \mathrm{~m} / \mathrm{s}$ and Poisson's ratio, 0.29.

In the Hopkinson bar technique, the induced wave propagation in a long elastic metallic bar has been used to measure the pressure produced during dynamic events (Dung et.al, 2011). The Hopkinson device is used to measure the dynamic stress-strain response of materials. A high precision strain gage, signal conditioners, and high speed digital oscilloscopes are used in Hopkinson bar which provides high sensitivity and accuracy. The sensitivity of the pressure bar is governed by the properties of the material of the bar such as, the density and the elastic wave impedance (Gray III, 2000). In addition, the type of stain gages and the characteristics of the associated instrumentations have an effect on the sensitivity.

The stress at the output bar is found by converting strain gages data (volts) to the stress by using following relations (Harrigan, 2005)

$$
\begin{gathered}
\sigma(\mathrm{t})=\frac{\mathrm{E}_{\mathrm{b}} \cdot 2 \epsilon v(\mathrm{t})}{\mathrm{G}_{\mathrm{g}} \cdot \mathrm{K}_{\mathrm{g}} \cdot v_{\mathrm{i}}\left(1+v_{\mathrm{B}}\right)} \\
\sigma(\mathrm{t})=\frac{\text { A.E. } \varepsilon_{\mathrm{t}}(\mathrm{t})}{\text { Ao }}
\end{gathered}
$$

Where, $\sigma(t)$ is the stress of transmitter bar as function of time, $\varepsilon v(t)$ is the strain gage voltage as function of time, $\mathrm{Gg}$ is the amplification factor, $\mathrm{Kg}$ is stain gage factor, $\mathrm{V}_{\mathrm{I}}$ is bridge input voltage, $\mathrm{Eb}$ is the elastic modulus of the bar, A is cross sectional area of the bar, Ao is the cross sectional area of the sample, $\sigma(t)$ is the transmitted axial strain pulses and $\nu_{B}$ is Poisson's ratio of the bar material. In addition, the time dependent strain rate and strain are calculated using the following equations:

$$
\begin{array}{r}
\varepsilon \cdot(t)=\frac{2 \mathrm{C}_{\mathrm{b} \varepsilon_{\mathrm{r}}}(\mathrm{t})}{\mathrm{Io}} \\
\varepsilon(\mathrm{t})=\int_{0}^{\mathrm{t}} \varepsilon^{\cdot}(\mathrm{t}) \mathrm{dt}
\end{array}
$$

Where $C_{b}, I_{0}$ and $A_{o}$ are the sound wave velocity, length and cross sectional area of the specimen respectively, and $\varepsilon(t)$ is the reflected axial strain pulses.

The Hopkinson bar technique is used to provide completer stress strain data as a function of strain rate. This is also used to determine the dynamic properties of numerous engineering materials; like ferrous and non-ferrous alloys, polymers, ceramics, and concrete (Forrestal et.al, 2002).

Additionally, it has been widely used to characterise soft materials, metal foams that have low mechanical impedance which is required increasing the sensitivity of testing device (Klepaczco, 1997; Kiernan et.al, 2009; Lopatnikov et.al, 2003; El-Nasri, 2005; Harding, 1960).

Split Hopkinson pressure bar has been used to measure the compressive mechanical behaviour of a material, loading samples in uni-axial tension, simultaneous compression torsion (Lewis \& Goldsmith, 1973).Also, it has been designed to measure the fracture 
toughness of an impact loaded material (Taylor, 1948). Metal matrix syntactic foams are characterised by using SHPB and the experimental setup and results are shown in Table 1 and Figure.9.

\begin{tabular}{|c|c|c|c|c|c|}
\hline & Sample ID & Weight (g) & Length (mm) & $\begin{array}{l}\text { Avg. Width } \\
(\mathrm{mm})\end{array}$ & $\begin{array}{c}\text { Velocity } \\
\text { applied }(\mathrm{m} / \mathrm{s})\end{array}$ \\
\hline Pre & \multirow[b]{2}{*}{ SHPB \#2 } & 12.6 & 16.84 & $21.40 \pm 0.1$ & \multirow[b]{2}{*}{21.6} \\
\hline Post & & 12.6 & 14.26 & $24.00 \pm 0.2$ & \\
\hline Pre & \multirow[b]{2}{*}{ SHPB \#3 } & 12.6 & 16.84 & $21.40 \pm 0.1$ & \multirow[b]{2}{*}{$35 \pm 1$} \\
\hline Post & & 3.6 & 3.69 & $29.00 \pm 1$ & \\
\hline Pre & \multirow[b]{2}{*}{ SHPB \#4 } & 11.5 & 17.04 & $20.60 \pm 0.5$ & \multirow[b]{2}{*}{$22.35 \pm 1$} \\
\hline Post & & 7 & 7.74 & $22.15 \pm 1$ & \\
\hline Pre & \multirow[b]{2}{*}{ SHPB \#6 } & 12 & 15.2 & $20.60 \pm 0.5$ & \multirow[b]{2}{*}{35} \\
\hline Post & & 2.1 & 2.63 & $27.50 \pm 1$ & \\
\hline
\end{tabular}

Table 1. Summary of experimental results of aluminium matrix syntactic foams under dynamic loading in SHPB.

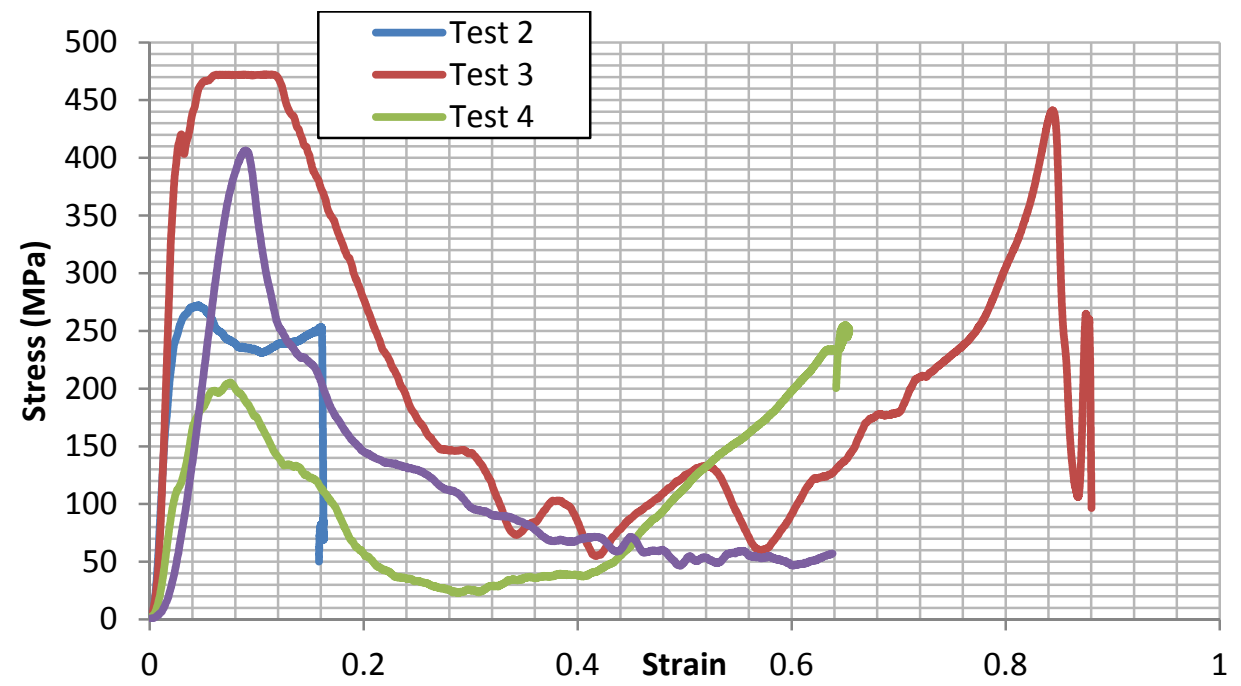

Figure 9. Stress-strain curve of aluminium matrix syntactic foam under dynamic loading of SHPB.

Dynamic compression testing showed a 10-30\% increase in peak strength compared to the quasi-static results. The strain rate sensitivities of these foams are similar to those of aluminium matrix composite materials as shown in Figure.10. These foams displayed excellent energy-absorbing capability. This suggests that these have potential for use in high loading applications or for impact protection in situations where a high plateau stress is desired (Balch et.al, 2005). 


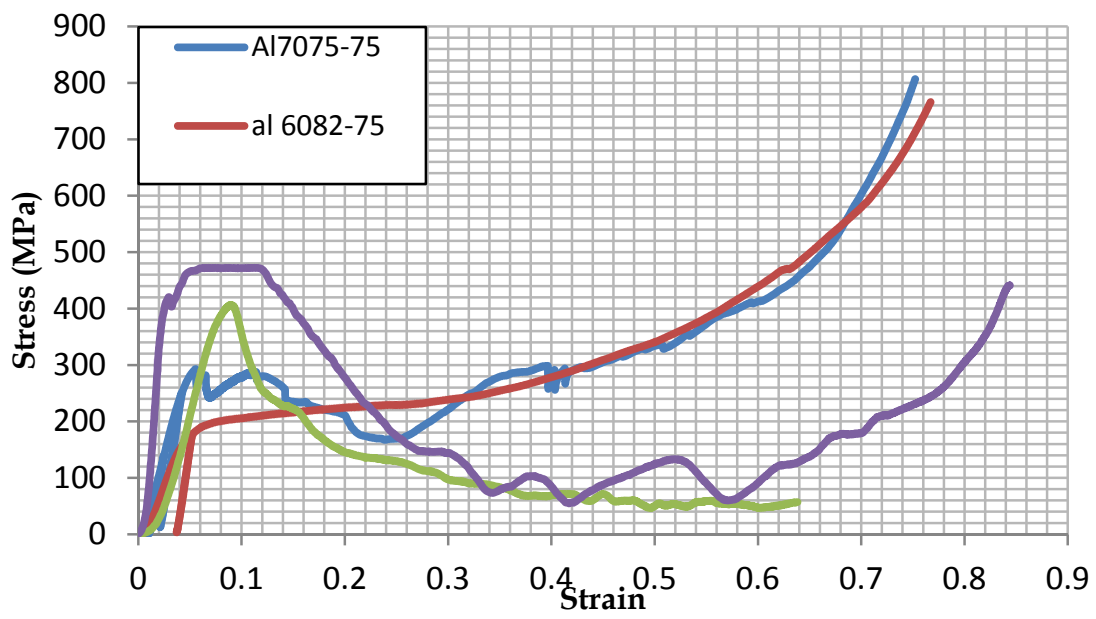

Figure 10. Stress-strain curve of aluminium matrix syntactic foam under static and dynamic loading.

High impact dynamic loading can be achieved by using high pressure gas gun (Cantwell\& Morton, 1991). Gas gun apparatus contains a breech, pump tube, transition section, launch tube and target tank as illustrated in Figure 11.

In addition to high speed camera this device can also record and analyse the moment of impact and post impact behaviour (Hazell et.al, 2010) and can monitor the behaviour of the projectile material during the impact.

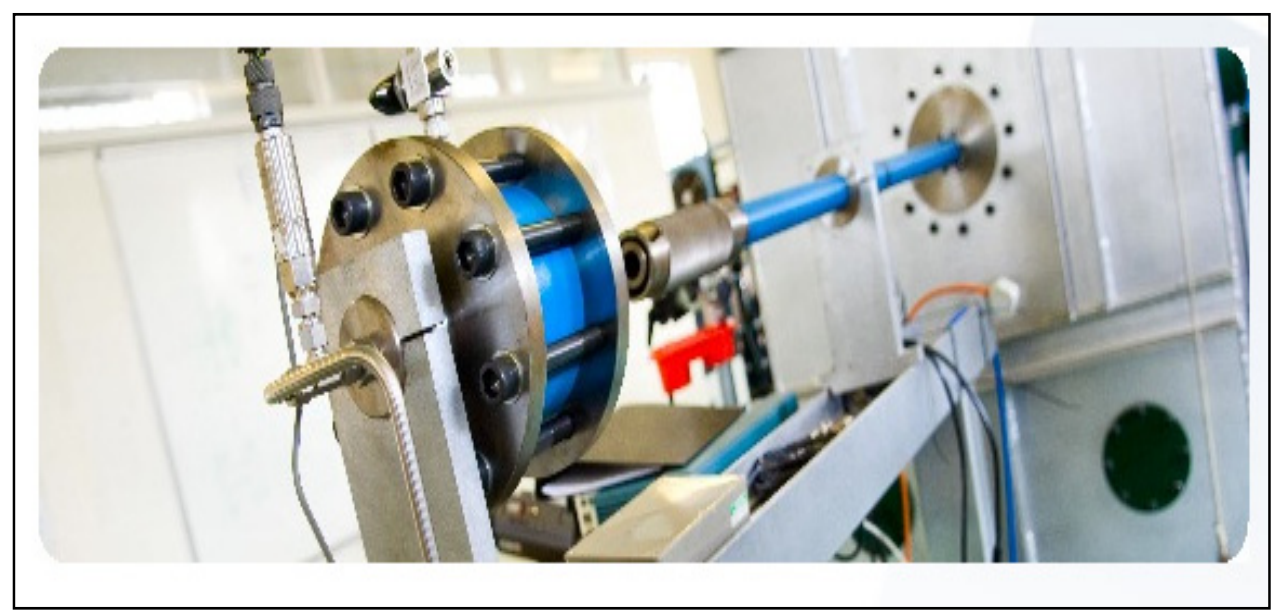

Figure 11. The gas gun testing apparatus (RMCS-Cranfield university)

In gas gun, a helium gas is used to accelerate a $12 \mathrm{~mm}$ diameter steel spheres to velocities approaching $620 \mathrm{~m} / \mathrm{s}$. The helium gas is pumped in to the breech at high pressure. An 
aluminium diaphragm blocks the release of the gas at the first stage. The diaphragm bursts and relieves the pressure when it reaches the required value. The helium gas is compressed which then heats up the volume of the gas by the polymer piston until the second diaphragm bursts. Consequently, the projectile and sabot is accelerated when the piston is at its final stage and the gas volume has expanded. The results of this test are shown in Figure. 12.

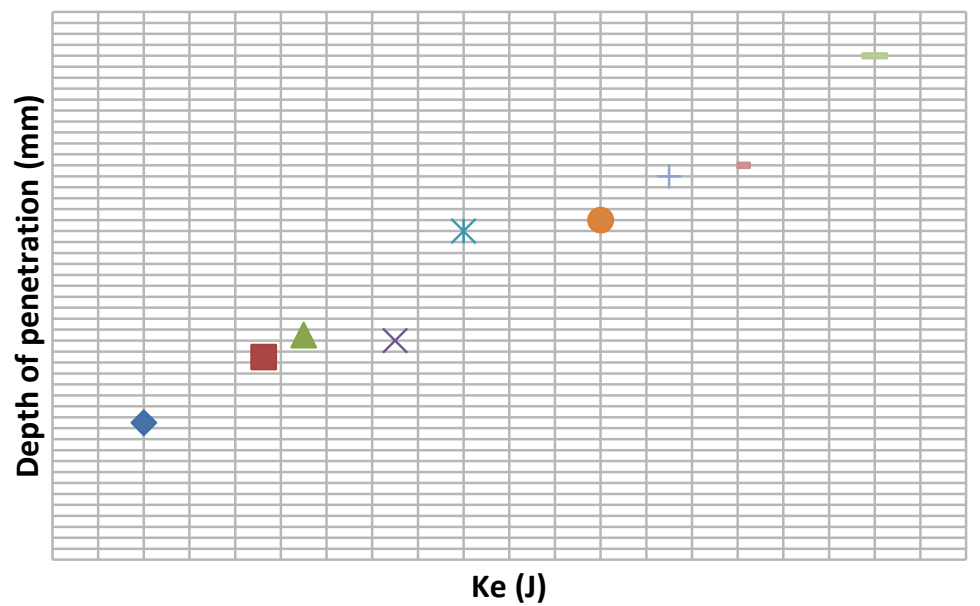

Figure 12. The kinetic energy of the impact against a depth of penetration in the material.

\section{Finite element modelling}

FEM was carried out by using ANSYS package (ANSYS, 2010). The matrix was identified by 10 nodded tetrahedron continuum elements called SOLID187 and SOLID186 in ANSYS, while for the microspheres ceramic walls SURF154 was used.

In Ansys/ workbench, the material was defined by inputting its mechanical properties that had been found by the static compression test. To define a material in Ansys/workbench, physical properties, linear elastic and plasticity of the material must be defined. The material must have a valid density defined for explicit or implicit simulation. Isotropic elasticity was used to define linear elastic material behaviour by defining Young's modulus and Poisson's ratio. However, the plastic deformation was computed by reference to Von Mises yield criterion. The multi-linear isotropic model was used to define the yield stress $\left(\sigma_{y}\right)$ as a piecewise linear function of plastic strain, $\varepsilon_{\mathrm{p}}$. The multi-linear isotropic model has been defined by introducing up to ten of stress-strain pairs.

A load of $100 \mathrm{kN}$ was imparted to aluminium matrix syntactic foam that had a dimension of $20 \mathrm{~mm} \times 20 \mathrm{~mm} \times 20 \mathrm{~mm}$. FEA is used to understand the stress distribution around the microspheres ceramics. In addition, the effect of the size of the microspheres and its volume fraction on the composite properties has been studied. Boundary condition was applied to 
the bottom of the sample that allowed the material to move freely in $\mathrm{X}$ and $\mathrm{Z}$ directions while Y-direction was fixed. The sample material had been defined as multi-linear isotropic hardening model.

It is found that, the Young's modulus increases with relative wall thickness, which means the particles wall thickness can be used to manage the deformation and fracture behaviour of syntactic foam. In addition, the location of the maximum stress is found on the inner surface of the particles as shown in Figure.13.

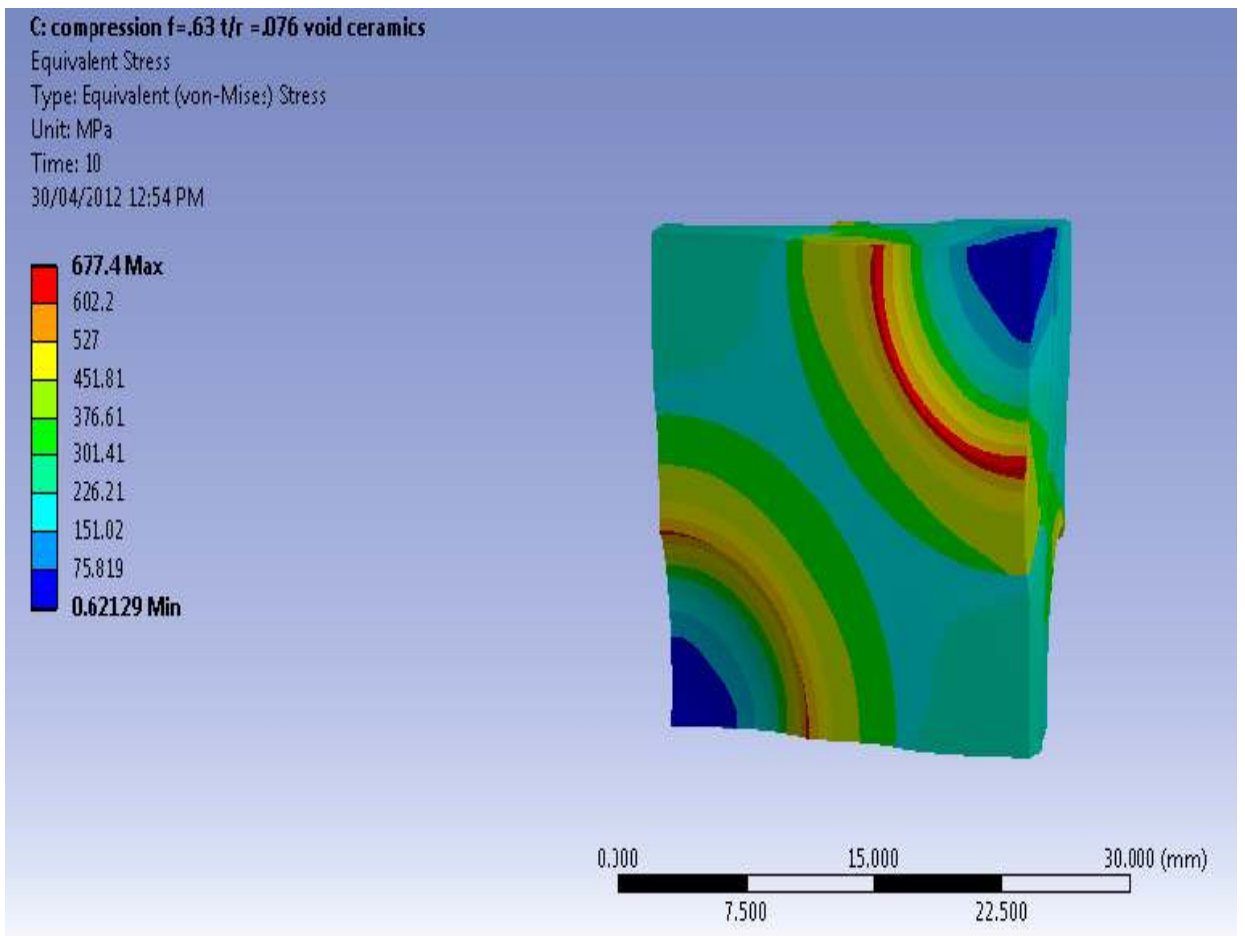

Figure 13. Maximum stress at the internal wall of the particles

\section{Summary}

- The ability to absorb high energy is the most desirable characteristic of metal matrix synthetic foam materials for use as a protective structure against dynamic loadings.

- The characterisation of the material was done by using quasi-static and dynamic loading. Static compression tests were conducted to find the stress-strain curve. The plateau stress and densification strain are found from those tests which are important properties to determine the energy absorption capability of materials.

- The effect of volume ratio of the metal matrix and the ceramic spheres on the mechanical properties of syntactic foam has, so far, not been thoroughly investigated. Therefore, the different failure modes of metal matrix syntactic foams were observed in previous studies. 
- The previous studies suggest that the simplest way to understand the failure mechanism of metal matrix syntactic foam is by comparing the failure modes of closed cell foam, in spite of the difference in the structure of the metal matrix syntactic foam that has ceramics instead of voids.

\section{Author details}

M. Altenaiji, G.K. Schleyer and Y.Y. Zhao

University of Liverpool Impact Research Centre, School of Engineering, Liverpool, UK

\section{Acknowledgement}

The authors would like to thank United Arab Emirates Government for sponsorship of this project, and also thank Mr Steve Pennington and Mr Rafael Santiago for their support during the experimental work and Dr L.P. Zhang for her assistance in preparing the syntactic foam samples, Dr. Ahmad Sheikh Rafi and Mrs Mariya Krates for her help.

\section{References}

Arnaud Fazekas, Luc Salvo, Remy Dendievel, Souhail Yossef, Peter Cloetenss, Jean Michel Letang, X-ray tomography applied to the characterization of cellular materials, related finite element modelling problems, Composite science and technology, Vol. 63, 2003, pages 2431-2443.

Balch, D.K. \& Dunand, D.C., Load partitioning in aluminium syntactic foams containing ceramic micro-spheres, Acta Materialia, Vol.54, 2006, pp. 1501-1511.

Beguefin, P. and Barbezat, M. 'Caracterisation mecanique des polymeres et composites 1 ' aide d'une machine d'essais rapide s, Proc 5th Journ e Nationale DYMAT, Bordeaux, France, 1989

Cantwell W., Morton J. Impact perforation of carbon fibre reinforced plastic, Composites science and technology, Vol.38, 1990, pp. 119-141.

Cantwell W.J. and Morton J., The impact resistance of composite materials -review, Composites, Vol. 22, Number 5, SEPT. 1991, pp.347-362.

Chen W., Lu F., Frew D., Forrestal M. Dynamic Compression Testing of Soft Materials, Journal of Applied Mechanics, Vol.69, 2002, pp. 214-223.

Dorian K. Balch, John G. O’Dwyer, Graham R. Davis, Carl M. Cady, George T. Gray III, David C. Dunand, Plasticity and damage in aluminium syntactic foams deformed under dynamic and quasi-static conditions, Material science \& Engineering, Vol.391, 2005, pp. 408-417.

Dorian K. Balch, John G. O’Dwyer, Graham R. Davis, Carl M. Cady, George T. Gray III, David C. Dunand, Plasticity and damage in aluminium syntactic foams deformed under dynamic and quasi-static conditions, Material science \& Engineering, Vol.391, 2005, pp. 408-417. 
Dou Z.Y., Jiang L.T., Wu G.H., Zhang Q., Xiu Z.Y. and Chen G.Q. High strain rate compression of ceno-sphere-pure aluminium syntactic foams, Scripta Materialia, vol. 57, 2007, pp. 945-948

Dung L., Gupta N., Rohatgi P. The high strain rate compressive response of Mg-Al alloy/ fly ash ceno-sphere composites, JOM, 2011, pp. 48-52.

Fanjing. Y, Geometrical effects in the impact response of composite structures, $\mathrm{PhD}$ thesis, University of Liverpool, 2010.

Gibson L.J. Mechanical behaviour of metallic foams, Mater Science, Vol.30, 2000, pp. 191-227.

Goldsmith W, Sackman JL. An experimental study of energy absorption in impact on sandwich plates, International Journal of Impact Engineering, Vol.12, Part(2), 1992, Pp. 241-262.

Gray III, G. T., Classic split-Hopkinson pressure bar testing, in ASM Handbook.Vol. 8: Mechanical Testing and Evaluation, ASM International, Materials Park, Ohio, 2000, pp. 462-476.

Hanssen AG, Enstock L, Langseth M. Close-range blast loading of aluminium panels. Int. J. Impact Eng., Vol. 27, 2002, pp. 593-618.

Harding J., Wood E.O., Campbell J.D., Tensile testing of materials at impact rates of strain, journal of Mechanical Eng. Sci., Vol.2, 1960, pp. 88-96.

Hazell P., Appleby-Thomas G., Herlarr K., Painter J. Inelastic deformation and failure of tungsten carbide under ballistic loading conditions, Materials science and engineering A, Vol.527, 2010, pp.7638-7645.

Hsiao, H. M., Daniel, I. M. and Cordes, R. D., Dynamic compressive behaviour of thick composite materials, Experimental Mechanics, Vol.38- 3, pp. 172-180, 1998.

Hsiao, H. M., Daniel, Strain rate behaviour of composite materials, Composites, part B 29B, 1998, pp 521-533.

I. Irausquín, F. Teixeira-Dias, V. Miranda, J.L. Pérez-Castellanos, Numerical modelling of the dynamic compression of a closed-cell aluminium foam, Universidad Carlos III de Madrid, 28911 Leganés, España.

Kiernan S., Cui L., Gilchrist M., Propagation of a stress wave through a virtual functionally graded foam, International Journal of Non-Linear Mechanics, vol. 44, 2009, pp. 456-468.

Kiser M., He M.Y. and Zok F. W., the mechanical response of ceramic micro-balloon reinforced aluminium matrix composites under compressive loading. Actra Mater, vol. 47, No.9, 1999, pp.2685-2694.

Kohnke P. ANSYS, Inc., 'Theory reference'. ANSYS Academic research-release 13.0, 2010.

Lewis J.L. and Goldsmith W., A biaxial split Hopkinson bar for simultaneous torsion and compression, Rev. Sci. Instrum., Vol.44, 1973, pp.811-813.

Lopatnikov S., Gama B., Haque M.J., Krauthauser C., Gillespie J., Guden M., Hall I., Dynamics of metal foam deformation during Taylor cylinder-Hopkinson bar impact experiment, Composite Structures, vol.61, 2003, pp. 61-71.

Lora j, Gibson and Michael F. Ashby (1997). Cellular solids structure and properties. 2nd edition. Cambridge, UK: Cambridge University press.

M. Altenaiji, G.K. Schleyer, Y.Y. Zhao. Characterisation of aluminium matrix syntactic foams under static and dynamic loading. Applied Mechanics and Materials Vol. 82 (2011) pp 142-147. 
N. Gupta, E. Woldesenbet, Micro balloon Wall Thickness Effects on Properties of Syntactic Foams, Journal of Cellular Plastics, Vol. 40, 2004, pp. 461-480.

Novak R.C. and De Crescente M.A., in composite Materials: testing and Design (second conference), American Society for Testing and Materials, Vol. 497, 1972, pp 311-323.

Palmer, R.A., Gao, K., Doan, T.M., Green, L. \& Cavallaro, Pressure infiltrated syntactic foams process development and mechanical properties, Material science and Engineering, Vol. 464, no.1-2, 2007, pp.358-366.

Rajendran R., Prem K, Basu S., B. Chandrasekar, A. Gokhale, Preliminary investigation of aluminium foam as an energy absorber for nuclear transportation cask, Materials and design, Vol. 29, 2008, pp. 1732-1739.

Roger L. Ellis (1996). Ballistic impact resistance of graphite epoxy composites with shape memory alloy and extended chain polyethylene spectra ${ }^{\mathrm{TM}}$ hybrid component, MSC, Faculty of the Virginia Polytechnic Institute and State, Blacksburg, Virginia.

Rohatgi P.K., Kim J.K. ,Gupta,Simon Alaraj N., Daoud A. Compressive characteristics of A356/fly ash ceno-sphere composites synthesized by pressure infiltration technique, Composites: Part A 37, 2006, pp. 430-437.

S. Barre, T. Chotard, M. L. Benzeggagh, Comparative study of strain rate effects on mechanical properties of glass fibre- reinforced thermoset matrix composites, Composites, Part A - 27A, 1996, pp 1169-1181.

Tao X.F. and Zhao Y.Y. Compressive behaviour of $\mathrm{Al}$ matrix syntactic foams toughened with Al particles, Scripta Materialia, vol. 61, 2009, pp. 461-464.

Taylor G.I., The use of flat ended projectiles for determining yield stress, part I: theoretical considerations, proc. R. Soc. (London) A, vol. 194, 1948, pp.289-299.

Vendra, L.J \& Rabiei, A study on aluminium-steel composite metal foam processed by casting, Materials Science and Engineering, Vol. 465, no. 1-2, 2007, pp. 59-67.

Wu G.H., Dou Z.Y., Sun D.L., Jiang L.T. , Ding B.S. and He B.F., Compression behaviours of ceno-sphere-pure aluminium syntactic foams, Scripta Materialia, Vol. 56, 2007, pp.221-224.

Xingfu Tao, Fabrication and mechanical properties of metal matrix syntactic foams, Liverpool University, PhD thesis, 2010.

Yiou S., High performance sandwich structures based on novel metal core, PhD thesis, University of Liverpool, 2009

Zhang L.P.and Zhao Y.Y. Mechanical Response of Al Matrix Syntactic Foams Produced by Pressure Infiltration casting, Journal of Composite Materials , Vol. 41, 2007.

Zhao H., El-Nasri I., Abdennadher S., An experimental study on the behaviour under impact loading of metallic cellular materials, International Journal of Mechanical Sciences, vol. 47, 2005, pp. 757-774.

Zhao H., Gary G., Klepaczco J., on the use of a visco-elastic split Hopkinson pressure bar, International Journal of Impact Engineering, vol. 19, 1997, pp. 319-330.

Zhao Y. Y. and Tao X. F., Behaviour of metal matrix under compression, in: Proceedings of Materials Science and Technology 2009, pp. 1785-1794. 